\title{
Bilateral simultaneous intertrochanteric fractures of femur without major trauma
}

This article was published in the following Dove Press journal:

International Medical Case Reports Journal

29 June 2015

Number of times this article has been viewed

\section{Ekrem Aydın \\ Turan Cihan Dülgeroğlu \\ Hasan Metineren \\ Department of Orthopedics and Traumatology, Dumlupinar University School of Medicine, Kutahya, Turkey}

Correspondence: Turan Cihan Dülgeroğlu

Department of Orthopedics and

Traumatology, Dumlupinar University

School of Medicine, 43270 Kutahya,

Turkey

Tel+905058346753

Email dr_turancihan@hotmail.com
Abstract: Bilateral simultaneous intertrochanteric femur fractures are rare and usually occur as a result of major trauma. In this paper, we present a 76-year old male patient from Turkey referred to the emergency service of our hospital with severe pain and poor mobilization in both hips. There was no history of major trauma. The patient was treated with closed proximal femoral nailing in both hips in the same operation period. At last follow-up, 6 months after surgery, the patient was able to walk with the aid of his children and resumed his previous status, after he had completed an intensive rehabilitation program.

Keywords: bilateral femur intertrochanteric fracture, PFN, elderly population

\section{Introduction}

Trochanteric femur fractures are observed frequently by orthopedic surgeons in daily practice in emergency services especially in the elderly patient population. They generally appear due to simple falls. ${ }^{1}$ Simultaneous bilateral femur intertrochanteric fractures are very rare and usually appear after major traumas or primary/secondary bone diseases. ${ }^{2}$ Although there are many case presentations in the literature about bilateral femoral neck fractures, there are very few case presentations about simultaneous bilateral femur intertrochanteric fractures. ${ }^{3}$ The proximal femur is the area where the most deficiency fractures are observed. In addition, the proximal femur is the area which is routinely subjected to maximum loading force. The deficiency fracture is a type of stress fracture caused by normal stress on abnormal bone. ${ }^{2}$ The proximal femur is a very important component of the motion system and receives high energy during movements because of carrying the whole of the body weight and due to the contractions of the muscles in this area. For this reason, the trochanteric femur fractures may occur in some cases where the bone mass is decreased and with the effects of the simple trauma and excessive muscle contractions together.

\section{Case report}

A 76-year old male from Turkey was referred to the emergency services of our hospital with severe pain and poor mobilization in both hips. In his history he had to jump over two small steps from a staircase, because his feet slipped and then the patient sat down on the step and was not able to stand up because he felt severe pain in both hips, and then he was transported to the emergency services later. The physical examination in the emergency service department revealed external rotation posture in both lower extremities, limitations in movement, sensitivity, and severe pain. After the X-ray and 
computed tomography, bilateral trochanteric femur fracture was detected (Figures 1 and 2). According to his medical history, even though the patient is elderly he does not have any medical comorbidities. The necessary preparations were made and the patient was taken to the operating room. Spinal anesthesia was applied, and fracture reduction was performed on the fracture table with the support of flouroscopy, and then in the same operation period, closed proximal femoral nailing was performed to both hips (Figure 3). No serious bleeding occurred, and based on this, there was no need for transfusion during and after the operation. No complications developed in the postoperative period. At last follow-up, 6 months after surgery, the patient was able to walk with his children's assistance and resumed his previous status, after he had taken up an intensive rehabilitation program.

\section{Discussion}

Although femur trochanteric fractures may be observed frequently in the elderly, bilateral fractures are very rare and usually occur after serious traumas. ${ }^{3-5}$ Those which occur after simple traumas are usually in the form of femoral neck fractures. ${ }^{7}$ These kinds of patients are usually osteoporotic patients. Unilateral trochanteric fractures may occur after simple traumas. ${ }^{5,6,9}$ Bilateral fractures are very rare and occur after serious complicated traumas. ${ }^{8,9}$ Besides the effect of the direct trauma, excessive and imbalanced contractions of the muscles in the same area also have an effect in these fractures. ${ }^{4,5}$ It is known that old bones lose their elastic adaptation capacity and this facilitates the occurrence of fractures. ${ }^{3}$ It must be kept in mind that in the basis of such fractures, there will always be osteoporosis, and the operation method must be chosen according to this fact. Also, the follow-up medical support must be considered in the light of this situation. ${ }^{5,6}$

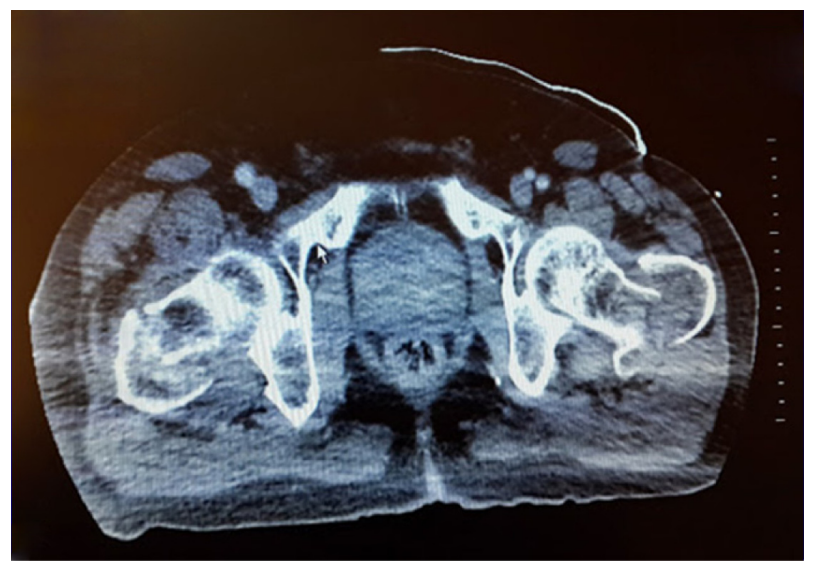

Figure I İnjury computed tomography image showing bilateral femur proximal fractures.

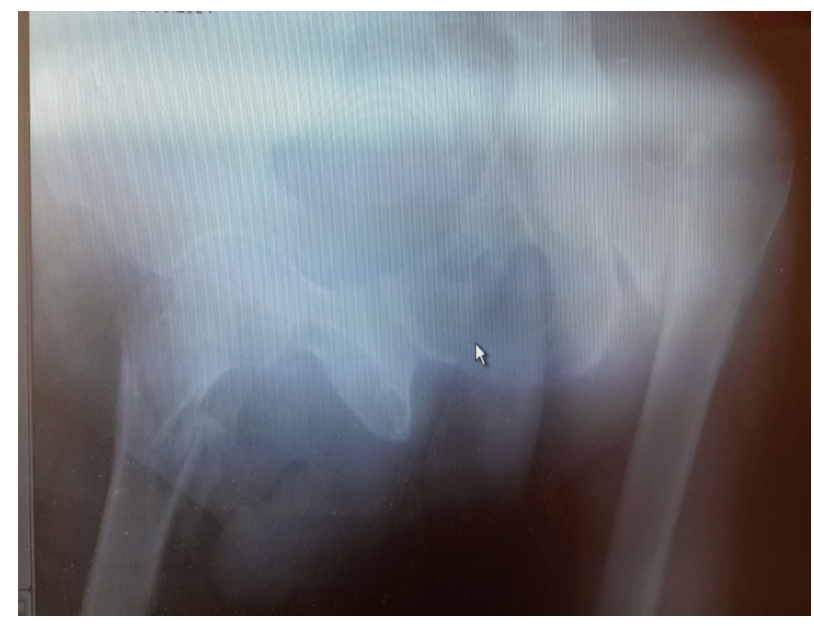

Figure 2 Anteroposterior plain radiography of both hips showing bilateral intertrochanteric femur fractures.

Intramedullary nails, sliding hip screws, anatomical plates, partial and total prosthesis, external fixators, and proximal femoral nails are among the materials used in the fixation of the fractures in this area. ${ }^{4,9}$ When both lower extremities are involved in the event, the fixation tool which will allow early mobilization and load of weight must be chosen. The treatment of extracapsular fracture of the hip relies on fracture pattern and stability. The sliding hip screw and plates generally are utilized for stable and displaced fracture pattern. The use of an intramedullary device is dedicated to unstable extracapsular femur intertrochanteric fracture and loss of medial cortical support of femur proximal fractures. ${ }^{10}$ Because this case is an extracapsular and unstable femur intertrochanteric fracture, we performed stable fracture fixation and preferred to apply the proximal femoral nail, which allows early mobilization and is easier tolerated by the patient. The proximal femoral nail application may be applied easily in such fractures; and since the hip abductor

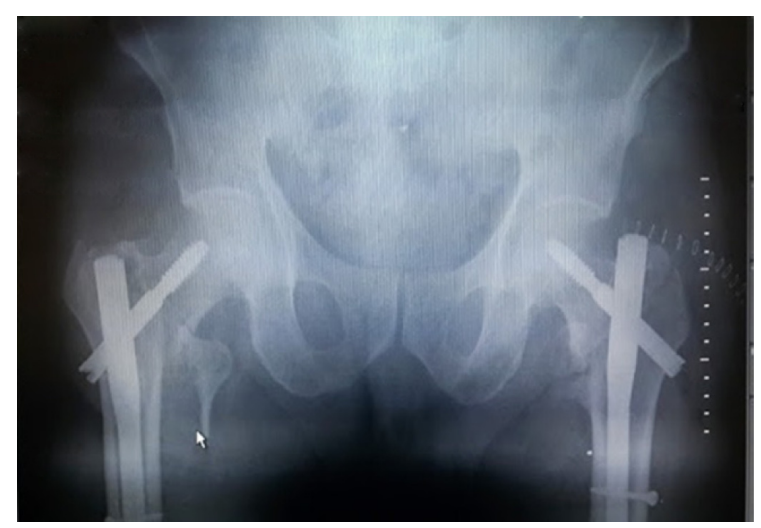

Figure 3 Postoperative X-ray showing bilateral proximal femoral nail implementation. 
and rotator mechanisms receive less damage iatrogenically during the surgery, the result is a more functional hip.

\section{Conclusion}

Bilateral trochanteric fractures are very rare injuries; however, sometimes they can occur especially in patients with osteoporosis after a simple fall or jumping. In the treatment, both the patient and the surgeon may have some challenges. In choosing the surgical fixation material, it is important that the material will allow early mobilization and protect the patient from any surgical complication, thus avoiding possible complications that can stem from long-term immobilization and surgical complication. Surgeons can be sure of a successful treatment with the choice of proper fixation material and accurate planning.

\section{Acknowledgment}

Written informed consent was obtained from the patient for publication of this case report and accompanying images.

\section{Author contributions}

Turan Cihan Dülgeroğlu, Hasan Metineren, Ekrem Aydın contributed equally to this work; Ekrem Aydın was in charge of this patient's care, including surgery and follow-up; Turan Cihan Dülgeroğlu and Hasan Metineren drafted and revised the manuscript and assessed the quality of the papers. All authors contributed toward data analysis, drafting and revising the paper and agree to be accountable for all aspects of the work.

\section{Disclosure}

The authors report no conflicts of interest in this work.

\section{References}

1. Grisoni N, Foulk D, Sprott D, Laughlin RT. Simultaneous bilateral hip fractures in a level I trauma center. J Trauma. 2008;65(1): 132-135.

2. Faraj AA. Bilateral simultaneous combined intra- and extracapsular femoral neck fracture secondary to nutritional osteomalacia: a case report. Acta Orthop Belg. 2003;69(2):201-203.

3. Rejev A. Bilateral Spontaneous İnter-Trochanteric Fractures of Proximal Femurs. Int J Surg Case Rep. 2012;5(5):246-248.

4. Copuroğlu C, Ozcan M, Dülger H, Yalnız E. Late-diagnosed Bilateral İntertrochanteric Femur Fracture During An Epileptic Seizure. Ulus Travma Acil Cerrahi Derg. 2012;18(1):92-94.

5. McGoldrick NP, Dodds MK, Green C, Synnott K. Management of Simultaneous Bilateral neck of Femur Fractures İn Elderly Patient. Geriatr Orthop Surg Rehabil. 2013;4(3):71-73.

6. Bouchoucha S, Barsaoui M, Saied W, Trifa M, Ben Khalifa S, Benghachem M. Bilateral stress fractures of the femoral neck fractures with no risk: a case report. Tunis Med. 2011;89(3):295-297.

7. Sood A, Rao C, Holloway I. Bilateral Femoral Neck Fractures in Adult Male Following minimal Trauma after Simple Mechanical Fall: A Case Report. Cases J. 2009;2(1):92.

8. Verma V, Kundu ZS, Batra A, Singh R, Sangwan SS, Gupta P. Simultaneous Bilateral Trochanteric Fractures a report of four cases. Clin J Traumatol. 2012;15(6):360-362.

9. Akçali O, Koşay C, Günal I, Alici E. Bilateral Trochanteric Fractures of The Femur İn a Patient with Chronic Renal Failure. Int Orthop. 2000; 24(3):179-180.

10. Koval KJ, Zuckerman JD. Hip Fractures a Practical Guide to Management. Springer-Verlag New York; 2000:142.
International Medical Case Reports Journal

\section{Publish your work in this journal}

The International Medical Case Reports Journal is an international, peer-reviewed open-access journal publishing original case reports from all medical specialties. Previously unpublished medical posters are also accepted relating to any area of clinical or preclinical science. Submissions should not normally exceed 2,000 words or

\section{Dovepress}

4 published pages including figures, diagrams and references. The manuscript management system is completely online and includes a very quick and fair peer-review system, which is all easy to use. Visit $\mathrm{http} / / / \mathrm{www}$.dovepress.com/testimonials.php to read real quotes from published authors. 